\title{
Ayla Çınaroğlu’nun Çocuk ve Gençlik Oyunlarına İdeolojik Yaklaşım
}

\section{Hasan ERKEK·}

\author{
Anadolu Üniversitesi
}

Özet

\begin{abstract}
Bu çalışmada, Ayla Çınaroğlu'nun, çocuk ve gençlik oyunları sadece ideolojik açıdan (teknik ve estetik açıldan değil) ele alınıp değerlendirilmektedir. Bu oyunlar, Miğfer, Boş Kaplumbağa, Tembel Fare Tini, Hoş Geldin Esin Perisi, Kim Demiş Niye Demiş ve Kăğt Şenliği adlı oyunlarıdır. Bu yapıtların her biri, önce irdelenerek, sonra yorumlanarak okunmakta, böylece, yapttlardaki ideolojik boyut ortaya çıkarılmaktadır. Ulaşılan sonuçlarsa çağdaş değerler açısından sorgulanmaktadır. İdeoloji, bu kısa çalışmada, ele aldı̆̆ımız tiyatro yapıtlarının anlam boyutu olarak değerlendirilecektir. Anlamin bir yapıtta nasıl yaratıldı̆̆g, nasıl örgütlendiği, o yapıtta hangi anlamin, anlamların yaratıldı̆̆ı ve yaratılan bu anlam/anlamların bazı düşünce sistemleriyle nasıl bir uyuşum ya da karşıtllk ilişsisi içinde olduğu, o yapıtın ideolojik boyutunu ortaya koymaktadır. Bütün yapttlarda olduğu gibi, anlam bütüncül olarak değil, küçük anlambirimleri, anlambirimcikleri halinde karşımıza çıkar. O anlambirimlerini, anlambirimciklerini iliş̧kilendirerek bir yoruma, oradan da oyunun derin anlamına ulaşmak, okurun o yapıtı özgür ve yöntemli okumasılyla olanaklı olabilecektir. Miğfer'de barışı; Boş Kaplumbağa'da özgün olmayl, farkllıklara sayg duymayl; Tembel Fare Tini'de "öteki”leştirmemeyi ve paylaşmayl; Hoş Geldin Esin Perisi'nde, yaratıcı olmayı ve bunun için çocukluktan kopmamayl; Kim Demiş Niye Demiş'te, sömürünün yeryüzünden yok olmasını ve eşitliğin kurulmasın; Kağglt Şenliği'nde ise bireyleşmeyi öne çıkarmaktadır. Sonuç olarak, anlam açısından bazı pürüzler bulunsa da, oyunlarının genelinde, Çınaroğlu'nun anlamı çok önemsediği, bilinçli bir çabayla onu yarattı̆̆, yaratılan bu anlamlarınsa çağdaş değerlerle örtüşsüğü gözlemlenmektedir. Ele aldığımız bu altı oyununda, eşitlikçi ve barış̧̧ıl bir dünya tasarımı sunduğu, bireyleşmeyi, özgün olmayı, yaratıcı olmayl, paylaşmayı öne çıkardlğı, bu değerleri yücelttiği görülmektedir. Çağdaş değerlerden insan haklarl, bireyleşme, özgürlük, eşitlik, demokrasi, bilimsellik, hukukun üstünlügü̆, barış, uzlaşma, çevre duyarlılı̆̆ gibi değerlerden, insan hakları, bireyleşme, özgürlük, eşitlik, demokrasi, barış değerlerini, çocuklar ve gençler için, çağdaş bir bakış açısılla ele aldığı ve işlediği sonucuna ulaşıyoruz. Buradan hareketle, Çınaroğlu'nun çağının sözcüsü bir sanatçılyazar olarak, çağının değerlerini yapıtlarında işleyerek yücelttiğini, bu nedenle çağdaş bir yazar olduğunu söyleyebiliriz.
\end{abstract}

Anahtar sözcükler: Ayla Çınaroğlu'nun çocuk ve gençlik oyunları, çocuk ve gençlik tiyatrosu, ideolojik yaklaşım, çocuk ve gençlik oyunlarında çağdaş değerler

\section{Abstract}

This paper attempts to treat and evaluate Ayla Çınaroğlu's plays for children and young people purely from ideological (not from technical and aesthetical) perspective. The plays included in this study are Miğfer (The Helmet), Boș Kaplumbağa (The Hollow Turtle), Tembel Fare Tini (Lazy Mouse Tini), Hoş Geldin Esin Perisi (Wecome Fairy of Inspiration), Kim Demiş Niye Demiş (Who Said It For What Purpsose) and Kăğt Senliği (Paper Festival). Each work is read in depth and evaluated so as to find out the ideological aspects of plays. The results are questioned with respect to contemporary values.For the purpose of this study, ideology is considered the meaning aspect of plays treated in the study. The ideological aspect of a work is concerned with how meaning is created in a work, how it is organized, which meaning(s) is created in the given work, and concordance and contrast relations of meaning/meanings with some though systems. In all works, we encounter meaning as little semantic units, not as a holistic system. Through reading works freely and methodologically, readers are able to relate semantic units with each other, come to an interpretation, and then reach the deep meaning of the play. The writer puts emphasis on peace in The Helmet, originality and respect for differences in The Hollow Turtle, avoiding "othering" and sharing in Lazy Mouse Tini, creativity and avoiding detachment from childhood in Welcome Fairy of Inspiration, eradication of exploitation in the world and establishment of equality in Who Said It For What Purpose, and individualization in Paper Festival. Consequently, it is observed that, despite the existence of some defects about meaning, Çinaroğlu attaches importance to meaning, and creates meaning through intentional efforts; and that these meanings identify with contemporary values. In these six plays, the writer presents a design of world dominated by equality and peace, and emphasizes and upholds values such as individualization, originality, creativity, sharing and so on. We can conclude that she treats values of human rights, individualization, freedom, equality, democracy and peace from a contemporary perspective for children and young people. On the basis of this finding, we can say that Çinaroğlu, as a writer who is the mouthpiece of her age, treats and upholds the values of her age in her works and that she is a contemporary writer.

Keywords: Ayla Cinaroğlu's plays for children and young people, theatre for children and young people, ideological approach, contemporary values in plays for children and young people 


\section{Giriş}

Dramaturjik yaklaşımından hareketle, Bernard Dort'un, sanat yapıtlarını teknik, estetik ve ideolojik açılardan ele aldığı sonucunu çıkarıyoruz. Yalnızca bir sanat yapıtını değil, o sanat yapıtı içindeki her ögeyi bu açılardan değerlendirip, herhangi bir ögenin, içinde yer aldığı yapıtta nasıl bir işlevi (teknik, estetik, ideolojik ya da iki-üç işlevi birlikte) yerine getirdiğini saptayabiliriz.

İdeoloji, 18.yüzyıl sonlarında Fransız düşünür Destutt de Tracy tarafından ortaya atılmış bir terimdir. Düşünürün, bu terimi “düşüncelerin bilimi”" anlamında felsefi bir terim olarak ortaya atmış olduğu belirtilmektedir (Williams, 1990).

İdeoloji, birbirleriyle ilişkili farklı alanlarda kulllanılan ve birçok alana yayılan bir kavramdır. Terry Eagleton, “ 'ideoloji' kelimesi farklı kavramsal liflerle bütün bir doku halinde örülmüş bir metindir” demektedir (Williams, 1990).

Günümüzde, ideoloji, özellikle sanat yapıtları söz konusu olduğunda, yapıtın "anlam” boyutunda karşımıza çıkmaktadır. "İdeolojik 'içerik' en dolaysız olarak söylemin anlamında ifade” edilmektedir. Zaten, ideoloji teriminin geldiği kök olan “idée", düşünce, fikir anlamında kullanılmaktadır (Williams, 1990).

İdeoloji, bu kısa çalışmada, ele aldığımız tiyatro yapıtlarının anlam boyutu olarak değerlendirilecektir. Anlamın bir yapıtta nasıl yaratıldığı, nasıl örgütlendiği, o yapıtta hangi anlamın, anlamların yaratıldığı ve yaratılan bu anlam/anlamların bazı düşünce sistemleriyle nasıl bir uyuşum ya da karşıtlık ilişkisi içinde olduğu, o yapıtın ideolojik boyutunu ortaya koyacaktır.

Bütün yapıtlarda olduğu gibi, anlam bütüncül olarak değil, küçük anlambirimleri, anlambirimcikleri halinde karşımıza çıkar. O anlambirimlerini, anlambirimciklerini ilişkilendirerek bir yoruma, oradan da oyunun derin anlamına ulaşmak, okurun o yapıtı özgür ve yöntemli okumasıyla olanaklı olabilecektir.

İdeoloji, düşünce ve anlamla ilgili olduğu için soyuttur. Oysa sanat yapıtları somuttur. Soyut kavramlar, düşünceler sanat yapıtına somutlanarak yedirilmiştir ve somut olarak yaratılmış olan sanat yapıtında yaratılmış olan anlam, okunarak, yorumlanarak soyutlama yoluyla ortaya çıkarılır.

Tiyatro yapıtlarında, anlam, kişiler, uzam, zaman, eylem-edimler, sözler, simgeler vb. aracılığıyla yaratılır. Okunurken de bu ögelerin anlam açısından irdelenmesi, yorumlanması gerekir. Öte yandan, tiyatro metinlerinde, zorunlu olmamakla birlikte (çünkü sözsüz tiyatro metinleri de vardır) söz de ağırlıklı yer tutabilir. Sözün olduğu her yerde anlam da vardır. Zaten "dilin anlam yönünü inceleyen bilim" olarak tanımlanan (Aksan, 1999) ve anlambilim adını taşıyan bir bilimin varlığı bilinmektedir. 
Oyunun irdelenerek okunmasından ve yorumlanmasından hareketle her oyunun konusu ve önermesi belirlenir. Bu da oyunun anlam boyutunun en damıtılmış halidir. Konu ve önermelerin ideolojilerle olan ilişkisi belirgin bir biçimde ortaya konmaktadır.

Konu, bir yapııı, hakkında yazıldığı şeydir. Oyunun temel problemidir. Önerme ise, o konuda ortaya konmaya, kanıtlanmaya çalışılandır. Lajos Egri, “önerme, evvelce tasarlanan ya da saptanan bir öneri; tartışmaya temel olan bir görüştür; belli bir sonuca götürmek üzere ileri sürülmüş ya da benimsenmiş bir öneridir” demektedir (Egri, 2004: s.20-21). Kuramcının yazarlar için tanımladığı bu kavram, okurlar için de geçerlidir. Yazarken yazara kılavuzluk eden bu öge okurken de anlamlandırma çabasına kılavuzluk eder. Okuma sürecinin sonunda ulaşılacak olan noktadır.

Konu ve önerme, soyut ve kavramsal düzeydedirler. Birer genellemeyi içerirler. Konu ile önerme arasında sıkı bir ilişki vardır. Konu ne ise, önerme de onunla ilgili olacaktır. Aksi halde ya yapıt ortaya konurken ya da alımlanırken anlam örgütlenmesinde bir sakatlık oluşmuş demektir.

Konuyu ve önermeyi ortaya çıkarmak sanıldığ 1 kadar kolay değildir. Herhangi bir yapıtı kaç farklı kişi okursa, o yapıtın o kadar farklı konu ve önermelerine ulaşmak olasıdır. Çünkü konu ve önerme yorumlama sonucunda ulaşılan kavramlardır ve sanat yapıtlarının bir tek doğru yorumu yoktur. Ama yapılan bütün yorumların, farklı kişiler tarafından belirlenen konu ve önermelerin tümünün metne dayanması, onu kapsaması ama ondan taşmaması beklenir.

Yapıtlarının ideolojik boyutu ortaya konduktan sonra, oradan hareketle yazarın ideolojisine ulaşılabilir (kuşkusuz, bunun için yazarın bütün yapıtlarının yöntemli olarak okunması gerekir) ve bu ideoloji çağdaş değerler açısından sorgulanabilir. Oradan da, yapıtlarına odaklanan yazarın çağdaş olup olmadığı değerlendirilebilir. Çünkü ideolojiler ve değerler arasında da bir bağlantı vardır.

Bu çağın başlıca değerleri olarak, insan hakları, bireyleşme, özgürlük, eşitlik, demokrasi, bilimsellik, hukukun üstünlügü, barış, uzlaşma, çevre duyarlılığı gibi değerler sayılabilir.

$\mathrm{Bu}$ çalışmada, Ayla Çınaroğlu'nun, çocuk ve gençlik oyunları sadece ideolojik açıdan (teknik ve estetik açıdan değil) ele alınıp değerlendirilecektir. Bu oyunlar, Miğfer, Boş Kaplumbağa, Tembel Fare Tini, Hoş Geldin Esin Perisi, Kim Demiş Niye Demiş ve Kağıt Şenliği (oyunlar basım tarihlerine göre sıralanmıştır) adlı oyunlarıdır. Bu yapıtların her birinin, önce irdeleyerek, sonra yorumlayarak okumaya, böylece, ideolojik boyutunu ortaya çıkarmaya çalışacağız. Ulaştığımız sonucu da çağdaş değerler açısından sorgulama içine gireceğiz. 


\section{Oyunların İdeolojik İrdelenmesi ve Yorumlanması}

\section{Miğfer (İlköğrenim çağı için)}

İrdeleyerek Okuma: Olaylar bir iç savaş sonucunda Alkent ile Verkent sınırında başlar, Alkent'te sürer ve sonuçlanır. Verkent'li askerler, Alkent'i ele geçirmek üzere sınırlarına dayanırlar. Verkent ordusu komutanı, "saldıracağız, dövüşeceğiz ve onları yeneceğiz" der. Verkent ordusuna bağlı askerler, saldırı öncesinde, dinlenmek için ormanın içlerine doğru çekilirler. Geride iki cana yakın asker olan Kat ile Kut kalır. Onlar da bulundukları yerde, miğferlerini çıkarıp dinlenmeye çalışırlar. Bu sırada rahat evlerini özlerler, savaşın kötülüğünden yakınırlar. Kat, karısını özlediğini söyler. Kut "Ne vardı şimdi gelip Alkent'e saldırcak yani? Ne güzel yaşayıp gidiyorduk işte. Alkentlilerin de bize bir zararları filan yoktu" der. Kısa bir süre sonra bazı sesler duyarlar? Alkentlilerin geldigini sanarak, korku ve panikle, miğferlerini orada unutup uzaklaşırlar. Gelenler Can ve Şan adında Alkentli iki kardeştir. Şan bir genç kız, Can ise onun küçük erkek kardeşidir. Unutulmuş miğferleri fark ederler. Ne işe yaradıkları konusunda bilgileri yoktur. Bir ara Can, şapka olabileceğini söyleyince, Şan, "Saçmalama, böyle ağır bir şapkayı ancak aptallar taşır kafasında" der. Tencere ya da sahan kapağı olabileceğini tahmin ederek alıp beraberlerinde Alkent'e götürürler. Kat ve Kut, miğferleri unuttuklarını fark edip geri dönerler ancak miğferleri bıraktıkları yerde bulamazlar. Komutandan çekindikleri için kampa dönmektense giysilerinin bir bölümünü çıkarıp miğferleri aramaya karar verirler. Şan ve Can, buldukları miğferleri, Alkent’te lokanta işleten annelerine götürürler. Anneleri ve dökümcü ustası da miğferlerin ne işe yaradığını bilmediği gibi nasıl bir işlevle kullanacaklarına da karar veremez. Sonunda miğferlerden birini sahan kapağı olarak vitrine, öteki de mutfağa kaldırılır. Çünkü Alkentliler savaştan uzak, barış içinde bir hayat kurmuşlardır. Hepsi barışçıl insanlardır. Kat ve Kut, Alkent'e, lokantaya gelirler. Sahan kapağı olarak vitrine konmuş olan miğferi görürler. Almak için yaptıkları girişimler, çeşitli vesilelerle sonuca ulaşmaz. Öte yandan, lokanta sahipleri Kat ve Kut'a çok iyi davranır. Şan ile Kut arasında duygusal bir bağ kurulur. Kat ve Kut, lokantanın yanındaki otelde çalışmaya başlar. Miğferler, otel duvarı süsü, meşale, meyvelik gibi çeşitli işlevlerle kullanılır. Vali meydanda bir toplantı yapar. Verkentlilerin sınırda görüldüğünü ama saldırgın amaçlarla gelmediklerini umduğunu söyler. Halkı barışçıl tutum için hazırlar. Oyunun sonuna doğru, Verkent askerleri Alkent'e gelir. Saldırmak isterler ancak karşılarında savaşçı askerler yerine konuksever bir halk bulurlar. Komutan ve askerler komik duruma düşer. Vali ve halk onlara karşılama töreni yapar. Dökümcünün miğferlerden yapmış olduğu meşaleler bu törende kullanılır. Oyunun son şarkısında "Kılıç yerine çiçek / Miğfer yerine meşale olsun / Güçlü güçsüze destek / Evren sevgiyle dolsun.” (Çınar, 1996). 
Simgeler ve işlevleri: Miğfer ve kılıç, militarizmi, miğfer'in askerlik alanı dışında (sahan kapağı, meyve tabağı, duvar süsü, meşale vb.) kullanılması sivil hayatı, çiçekler barışı ve mutluluğu simgeler niteliktedir.

Yorumlama: Oyun için tipik bir durum seçilmiş. Düşman iki kardeş ülke var. Eskiden bir olan, daha sonra bölünmüş ve birbirine düşman olmuş iki küçük ülke. Tıpkı Kıbrıs, Kore, eski Federal Almanya gibi.

Verkent ile Alkent karşıtlık oluşturacak iki model ülke. Biri savaşa yatırım yapmış öteki barışa. Biri saldırgan öteki savunmacı. Verkent askerleri Alkent'e saldırınca, Alkentliler benzer bir biçimde karşlık vermezler. Kılıca çiçekle karışılık verirler. Onlara konuksever davranırlar. Bu da Verkent askerlerinin ezberini bozar. Savaş çıkmadığı gibi komik sonuçlar doğar. Buradan da, savaşın, rekabetin en kızgın, en can yakıcı hali olduğu söylenebilir.

Miğfer savaş araçlarından biri olarak başrolde gibidir. Bir üretim aracı değildir. Barış içinde bir işlevi yoktur. Barış atmosferinde ona da bir işlev aranır. Böylece, savaşın saçmalığı daha iyi vurgulanmış olur. Barış atmosferinde Miğfer'e bulunan kimlikler ve işlevler hep barışa hizmet edecek işlevlerdir. Sahan kapağ 1 , meyve tabağı, duvar süsü, şenlik meşalesi hep olumlu işlevlerdir.

\section{Konu: Barış}

Önerme: Savaşmak yerine dost olmak, çatışmak yerine uzlaşmak, barışı kurmak gerekir. Barışı inşa etmek savaş araçlarıyla değil, barış araçlarıyla olanaklıdır.

Boş Kaplumbağa (Okul öncesi ve ilkokul çağı için)

İrdeleyerek Okuma: Ormanda, hayvanlar arasında geçer. Başkan olmak isteyen Kamplumbağa’yı tanırız. Ormandaki bütün hayvanların akılsız olduklarını, en akıllı hayvanın kendisi olduğunu ileri sürer. Ona göre, kuşlar uçarak, köstebek yer altında yaşayarak yanlış bir hayat sürmektedirler. Herkes kendisi gibi evini sırtında taşımaladır. "Tüm hayvanlar, evlerini yıkmalı, kendilerine benimki gibi birer taşınır ev yapmalılar" der. Geyiklerin boynuzları, tavşanların kulakları, sincapların kuyrukları da gereksizdir. Başkan olunca, bütün bu "fazlalık”ları koparmak, hayvanları tektipleştirmek azmindedir. "Ah, bir başkan olsam ben, / Neler yaparım neler... / Yasaklanır ne varsa saçmasapan / Gereksiz bütün şeyler / Arsızca açan çiçekler / Çılgınca akan sular / Kırıtan kelebekler / Uzun kuyruklar / Uzun kulaklar / Uzun bıyıklar / Büyük kanatlar / Büyük boynuzlar / Kükremeler, ulumalar / Koşmalar, gülmeler, oynamalar / Yasak bundan böyle...” Daha sonra bunun kıskançlıktan kaynaklandığı, kendisinde olmayan şeyleri yok etmek istediği anlaşılır. Oyunun ikinci bölümünde ise, her hayvanın bir organını (kuyruk, boynuz, kanat vb.) alarak kendisinde yeni ama sahte bir hayvan yaratır. Bu haliyle başkan olmak ister. Ancak gelişen komik olaylarla komik duruma düşer. Hatasını anlar ve kendisiyle barışık bir halde yaşamanın önemini 
anlar. Ormandaki öteki hayvanlar da onu sevmeye devam edeceklerdir. Ormanın tehdit edilen hayatı bozulmadan devam edecektir.

Yorumlama: Adorno, hayatı aşırı estetize etmenin de bir çeşit faşizm olduğuğunu söylemektedir. Kaplumbağa'nın ormandaki farklılıklara sayg1 duymaması, hayvanları ve onların hayatlarını tektipleştirme, kendine benzetme eğilimi eleştirelmektedir. Özgün olma ve özgünlüklere, farklılıklara saygı duyma, herkesin kendi doğasına uygun yaşaması öne çıkarılmaktadır. Tek kültürlü yaşam yerine çok kültürlü yaşam savunulmaktadır.

Konusu: Özgün ve Farklı Olma

Önerme: Kişi özgün olmalı, kendi doğasına göre ve kendisiyle barışık yaşamalı, farklılıklara saygı duymalıdır.

Tembel Fare Tini (Okul öncesi ve ilkoul çağı için)

İrdeleyerek Okuma: Tıpkı insanlar gibi yaşayan fareler dünyasında, Tini küçük bir faredir. Özelliği tembel olması, bütün gün televizyonun karşısında oturması ve bundan büyük mutluluk duymasıdır. Şini adındaki arkadaşı onu ziyarete gelir. Ortak arkadaşlarıyla birlikte piknik düzenlediklerini belirterek Tini'yi de davet eder. Tini istemeye istemeye katılır. Bir tek iyi tanımadıkları ve yaptığı açgözlülüklerden dolayı hoşlanmadıkları arkadaşları Açgöz’ü davet etmezler.

Tini, piknik sırasında da tembelliğinden kurtulamaz. Hiçbir oyuna katılmaz, oturmayı tercih eder. Arkadaşları da yiyecekleri koruma görevini ona verirler. Oyundan sonra birlikte yiyeceklerdir. Ancak tembel Tini uykuya dalar. O arada, tesadüfen oraya gelen Açgöz, arkadaşlarının kendisinden habersiz pikniğe geldiklerini görünce çok kızar. Tini'nin de uyumakta olduğunu firsat bilip yiyeceklere saldırır. Bir kısmını yer, bir kısmını alıp oradan kaçar. Tini son anda Açgöz'ü fark eder. Bunu arkadaşlarına söyler. Ancak, yiyecekleri Tini'nin yemiş olabileceğini düşünen arkadaşları ona inanmazlar. Tini ise, tembel olduğunu ancak yalancı olmadığını söyleyerek oradan uzaklaşır. Üzüntüyle evine döner.

Şini ve Açgöz karşılaşırlar. Açgöz, Şini'nin fırıldağını almak için yanaşınca, Şini onun yakasındaki yemek lekelerini görür ve yiyecekleri onun yemiş olduğunu anlar. Bu bilgiyi arkadaşlarıyla paylaşır. Hep birlikte, özür dilemek üzere Tini’nin evine giderler. Tini'den özür dilerler. Açgöz’e kızgınlıklarını dile getirirler. Ancak, Tini’nin annesi, “Ama kötü olmasının da bir nedeni vardır belki. Bunu hiç düşündünüz mü?” diye sorar. Daha anlayışlı olmalarını, Açgöz'ün kötülüklerinin arkasında mutsuz olma olasılığının olabileceğini ve onu dışlamamaları gerektiğini söyler.

Küçük fareler, eskimeye yüz tutmuş ve kullanılamaz olmuş Farecik Parkı'nı kurtarmak ve Açgöz'ün doğum gününü kutlamak üzere bir parti düzenler. Ama Açgöz'ün bundan haberi yoktur. Ona büyük sürpriz olur. Açgöz daha önce yaptıklarından çok utanır, onlardan özür diler. Arkadaşlarından, ona 
becerilerini öğretmelerini rica eder. Onlar da memnuniyetle bu isteği kabul ederler. Adı Tokgöz olarak değiştirilir. Arkadaşlıkları pekişir.

Yorumlama: Oyunda birbirini tamamlayan iki anlam katmanı göze çarpmaktadır.

Birincisi, arkadaşları Açgöz’ü aralarına almadıkları onu dışladıkları için onu “öteki”leştirmişlerdir. Bunun sonucunda o da saldırganlaşmıştır.

İkincisi, Açgöz'ü yeniden aralarına almaları ve önemsemeye başlamaları onun bu saldırgan tutumunu bırakmasına neden olur. Paylaşmak da mutluluk getirecektir.

Ancak oyun, Tini üzerinden üretilen anlam açısından bir eksiği de barındırmakta bu da anlamın çatısı bakımından bir çelişkiye neden olmaktadır. Bilindiği gibi, oyunun adı Tembel Fare Tini'dir. Anlatı kadar anlamın da Tini üzerinden üretilmesi beklenir. Oysa Tini ile başlayan oyun Açgöz üzerine kaymakta, onun dönüşme serüveni konu edilmektedir. Dışlanmış olan Açgöz, onaylanıp gruba katılınca dönüşmekte, adı da Tokgöz olmaktadır. Buradan da önemli bir anlam üretilmektedir. Ancak, oyunun başat kişisi olan Tini üzerinden bir değişim, dönüşüm hemen hemen yaşanmamaktadır. Gerçi oyunun sonunda annesi oğlu Tini’nin daha hızlı olmasını diler ve Tini de bu dileğe katılır ama bu pek bir dönüşüm sayılmaz. Öte yandan, oyunun sonundaki şarkılar, tembelliğin kötü olduğu yönündedir. Ancak oyun içinde Tini'nin tembelliği pek bir kötülüğe, soruna neden olmamıştır. Dahası Açgöz’ün kazanılması yönünde“olumlu” bir sonuç doğurmuştur. Oyunun başında tembel olan Tini ise, oyunun sonunda da tembeldir. $\mathrm{Bu}$ da, adı, temel kişileri ve anlam ilişkisi açısından oyunu zedelemektedir. Okuru, kimler ve hangi olaylar üzerinde anlam üreteceği yönünde çelişkiye düşürmektedir.

Değişim, dönüşüm yaşamayan Tini yerine Açgöz üzerinden üretilen anlamı göz önüne aldığımızda karşımıza şöyle bir konu ve önerme çıkmaktadır.

Konu: Ötekileştirme / Paylaşma

Önerme: Paylaşım olmazsa, barış bozulur. Barışın yeniden tesisi ancak paylaşımla mümkündür.

Hoş Geldin Esin Perisi (İlkgençlik çağı için)

İrdeleyerek Okuma: Yazar Metin Esengiloğulları, yetişkinler için yazan bir yazardır. Yazdıkları, geç basılmakta, az satılmaktadır. Yayıncısı ise işi ağırdan almakta, yazar Metin'e olan borçlarını ödemekte özenli davranmamaktadır. Metin sıkıntılarla boğuşurken, yayıncı Semih Bey çıkagelir. Çocuklar için bir dergi çıkaracaklarını söyleyerek, Metin'den de bir öykü yazmasını ister. Böylece, kalan alacağıyla birlikte öykünün parasını da peşin olarak ödeyecektir. O güne kadar çocuklara yönelik olarak hiç öykü yazmamış olan Metin, mecburen böyle bir öykü yazmaya kalkışır. Ancak, ne yazacağını bilemez. İlham Perisi çağırır ancak, sevimli, enerjik, candan bir Esin Perisi çıkagelir. Çantasında, ip, elma, keman, 
şapka gibi çocukların da seveceği nesneler vardır. Onlarla, Metin'in yazacağı öyküye esin bulmak ister ancak, Metin bir türlü ilerleyemez. Aralarında muzip bir tartışma, tatlı bir kavga başlar. Derken, yazarın kızkardeşi, kızı Funda'yı ona bırakmak üzere çıkagelir. Toplantıdayken, Metin'den Funda’ya göz kulak olmasını ister. Oyun daha da eğlenceli bir hal alır. Funda, Esin Perisi’nin verdiği esinlerden daha kolay esinlenir ve birçok öykü oluşturur. Metin de o öyküleri daktilo eder. O ana kadar Esin Perisi, yazar Metin'den başkasına görünmezken, bu kez Funda'ya görünmeye, Metin içinse görünmez olmaya başlar. Artık onun esin perisi değildir. "Artık beni göremez ve işitemez....Çünkü istifa ettim” der. Sonunda da Funda'yla birlikte onların evlerine gitmeye karar verir. Metin'se yeni bir Esin Perisi bulmuştur. O da Funda’dır. Esin Perisi Metin'e "'Haydi bakalım, sana bir esin perisi daha geldi. Ne şanslı adamsın. Gene de bir öykü, ya da bir masal yazamazsan, bilmem artık" der. Esin Perisi oradan ayrilır. Ancak, yeni esin perisi Funda bundan böyle Metin'in evine daha sık gelmeye başlayacaktır.

Simgeler ve işlevleri: Araba, yazarın esin belleğini, elma, altın ip, yeşil şemsiye, keman, mavi balon, süslü şapka, tavşan ve oyuncak fare ise, çocukluğu simgeler gibidir.

Yorumlama: Oyunda iki anlam katmanı olduğu anlaşılmaktadır. Bunlardan, birisi yazar Metin üzerinden üretilmektedir. Metin, evlenmemiş, çocuk babası olmamıştır. Hayattan ve çocuklardan uzak kalmış, biyolojik olarak olduğu gibi yazar olarak da kısır kalmıştır. Gelen Esin Perisi'nin çabaları da onu yazar olarak doğurgan kılmaya yetmemiştir. Ancak yeğeni Funda'nın eve gelmesiyle ve onun katkısıyla beklenen öyküyü yazmaya başlar.

İkinci anlam ise, Esin Perisi ve Funda üzerinden üretilir. Siz yaratıcı değilseniz, Esin Perisinin yapabileceği pek bir şey yoktur. Zaten yetişkinlerin hayal gücü zayıftır, Esin Perisi onu hayata geçirmekte zorlanır. Çocukların hayal gücü daha geniş olduğundan Esin Perisine ihtiyaçları yoktur ama Esin Perisi de onları sever ve onlarla kalır. Hatta onlandan hiç ayrılmaz.

Konu: Yaratıc1lik

Önerme: Yaratıcı düşgücünü yitirmemek için çocuklarla olan bağı koparmamak gerekir. Onların düşgücü daha zengin olduğundan daha yaratıcıdırlar.

Kim Demiş Niye Demiş (ilkgençlik çağı için)

İrdeleyerek Okuma: Gençlerin Dede'den masal anlatmasını istemeleriyle gerçekçi bir biçimde başlayan oyun, masalın anlatımı ve Dede ile gençlerin masal kahramanlarının rollerini de oynamaya başlamalarıyla birlikte fantastik bir düzeyde sürer. 
Dede'nin anlattığı masala göre, adı konmamış bir zamanda ve uzamda (tarımla ve hayvancılıkla geçinen bir köyde) Kara Yusuf adında bir delikanlı yaşamaktadır. Kara Yusuf'un kendinden büyük iki erkek kardeşi daha bulunmaktadır. Babaları iki büyük oğlunu zengin düğün dernekle evlendirip onlara yeteri kadar mal mülk verirken, sıra küçük oğul Kara Yusuf’a gelince, onu düğünsüz derneksiz evlendirmekle kalmaz, mal mülk vermekte de cimri davranır.

Olayların bundan sonraki bölümü, Dede de dahil olmak üzere sahnedekilerin rol almalarıyla sahnede canlandırılmaya başlanır.

Kara Yusuf'un üç kızı olur. Karınca kararınca elindekilerle geçinmeye çalışır. Ancak bir süre sonra bunun pek olanaklı olmadığını görür. Gelir kaynaklarını geliştirmek için bir kese altın düşleyip bunu dile getirince, Cinfoznah adında, dazlak başlı, iri, şişman gövdeli biri belirir. Elinde metal bir baston, ayaklarında metal çarıklar, elinde de metal bir kuş vardır. Kara Yusuf'a kendisiyle ülkesine gelir de onun için çalışırsa, ona günde üç altın vereceğini söyler. Böylece Kara Yusuf altınları biriktirebilecek, onlarla tarımını geliştirebilecektir. Karısı ve kızları duruma üzülse de çaresiz kabul ederler. Kara Yusuf Cinfoznah'ın sopasına binerek onun ülkesine uçar. Her şeyin sistemli olduğu zengin bir ülkedir burası. Ekmek dışında her şey ağaçlarda bulunmaktadır. Kara Yusuf firında çalışır. Çalışmasının karşılığı olarak her gün robottan üç altın alır. Ancak onları biriktiremez. Çünkü her şeyin bedeli vardır. Altın vermeden hiçbir şey elde edemez. Kazandığı altınlardan biri ile günde bir ekmek alır. Yalnızlık çektiği için odasına Sarıperi dadanır ondan kurtulmak için her gün ona da bir altın vermek zorunda kalır. Böylece elinde sadece bir altın kalır.

Böyle altın biriktiremeyeceğini anlayınca, ülkesine gitme isteğini Cinfoznah’a iletir. Bunun üzerine Cinfoznah, isterse karısını ve çocuklarını da getirebileceğini, Sarıperi'nin kalabalıktan korktuğunu, kendisini rahat bırakacağını söyler. Kara Yusuf denileni kabul eder. Karısını ve kızlarını da yanına aldırtır. Ancak bu kez de giderleri artmıştır. Yine altın biriktiremez.

Bir kez daha dönmeye karar verince bu kez Cinfoznah karısını da işe alabileceğini, günde beş altın ödeyebileceğini söyler. Kara Yusuf kabul eder. Böylece durumları biraz toparlanır ancak bu kez de başka sorunlar çıkar. Kızları ağaçlardan bir şeyler koparmaya çalışınca rehin alınırlar. Kara Yusuf ve karısı onları kurtarmak için bütün altınlarını vermek zorunda kalırlar.

Sorunlar bununla da bitmez, Sarıperi iki büyük kızı, tek tek ele geçirip kendisine benzetir. Kara Yusuflar onları geri almak istese de başaramaz. Çünkü Sarıperi her birine karşılık yüz altın ister.

Sonunda, çözümü küçük kız bulur. Annesinden Cinfoznah için bir çorap örmesini sağlar. Bunu söylediklerinde, Cinfoznah bu karşıllksız hediyeye çok sevinir. Çorabı denemek için elindekileri küçük kıza verince, küçük kız onlarla uçmaya başlar. Cinfoznah güçsüz kalmıştır. Önce, kızları kurtarmak için 
Cinfoznah'tan altın alıp Sarıperi'ye verirler. Sonra da aile olarak, Cinfoznah'ın uçma araçlarına (metal çarık, metal baston ve matal kuş) binerek köylerine dönerler. Ardından da bu araçları ona geri gönderirler. Ancak araçlar dönüş yolunda parçalanıp dağılır. Toprağa, suya ve havaya karışırlar.

Simgeler ve işlevleri: Kara Yusuf'un babasının mallarını üç oğlu arasında pay etmesi tarıma dayalı feodal sistemi; Dazlak başlı, iri, şişman gövdeli Cinfoznah zengin, sömürgeci toplumları; Kara Yusuf ve ailesi geri kalmış, sömürülen doğu ülkelerinin halklarını; metal baston, metal kuş, metal çarıklar, sömüren ülkelerin teknolojik güçlerini (uçak vb); altın saçlı Sarıperi, metalaşan kadınları; üzerlerinde her şeyi olan ağaçlar, kapitalist ülkelerde malların sergilendiği vitrinleri; altınlar parayı simgeler gibidir.

Yorumlama: Gerçekçi bir masalı ya da masalsı bir gerçeği dile getiren bu oyunda üretilen anlamlar çelişkili gibi görünmekte, iki farklı okumaya olanak tanımaktadır.

İlk ve önemli anlam, anlatı üzerinden üretilmektedir. Geri kalmış, feodal bir toplumdan gelişmiş, kapitalist bir topluma yapılan ama orada tutunamayıp geri dönülen bir yolculuğa tanık oluruz. Oyunun olumlu kişileri, bu kapitalist sistemi aşma yönünde değil, geri çekilme yönünde adım atmıştır. Köylerine geri dönmeyi seçmişlerdir. Böylece, bir başarısızlı̆̆ın yanı sıra, bir içe kapanma anlamı da üretilmektedir. Dönülen yer "azıcık aşım, kaygısız başım” diyecekleri köyleridir. "Sıska öküz ne sürdüyse, taşlı tarlada ne bittiyse, cılız koyun ne verdiyse" onlarla yetinmek zorunda kalacaklardır. Emeklerini, zamanlarını yitirip yine yoksul hayatlarına dönmüşlerdir. Sarıperi’ye benzetilen kızlarını göz önünde tutacak olursak, bu serüvenden yaralar da aldıkları söylenebilir. Sergilenen olaylar açısından kapitalist sistem eleştirilirken anlatı nedeniyle tutucu bir tuzağa düşüldüğü görülmektedir.

Üretilen ikinci anlam daha olumlu gibidir. Hileyle elde ettikleri (bu da sorgulanabilir), metal çarık, metal baston ve metal kuşla temsil edilen kapitalist ve teknolojik gücü geri gönderirler. Ancak, gücü temsil eden bu araçlar sonunda gökyüzünde parçalanıp dağılmaktadır. Her bir araç bir yere düşüp yitmektedir. Böylece, güç yok olmakta, suya, toprağa havaya karışmaktadır.

Bununla birlikte, oyunda başka eleştiriler de vardır. Feodal sistemin erkek egemen olduğu ve adil olmadığı vurgulanmaktadır. Kara Yusuf'un iki erkek kardeşi daha vardır. Ancak hiç kız kardeşi yoktur. Ayrıca annelerinden de söz edilmez. Babaları mallarını adil olmayan bir biçimde üç oğlu arasında paylaştırır. Kara Yusuf’unsa üç kızı doğar. Böylece, dolaylı olarak, erkek egemen toplum eleştirilmekte, kadınlardan yana dengeyi düzeltme yoluna gidilmektedir.

Böylece, bir konuda iki farklı önerme karşımıza çıkmaktadır.

Konu: Eşitsizlik ve Sömürü

Önerme 1: Hem feodal sistem hem de kapitalist sistem sömürü düzenleridir. Başkalarının zenginlik dolu kapitalist sisteminde yaşamaktansa kendi geri kalmış feodal düzenimizde yaşamak daha iyidir. 
Önerme 2: İnsanlar eşittir, dünyanın nimetlerinden eşit bir biçimde yararlanmalıdırlar. Mevcut sistemler, zayıf olanı, küçük olanı, farklı olanı ezmektedir. Zayıfı, yoksulu, farklı olanı ezen güç ve sistemler yok olmalıdır.

\section{Kağıt Şenliği (İlköğretim çağı için)}

İrdeleyerek Okuma: Aydan adındaki kız çocuğu kızamık olmuştur. Arkadaşlarına da bulaşmaması için onlarla görüşmesi uygun görülmemektedir. İyileşmeye başlamıştır ancak bir süre daha evde dinlenmesi gerekmektedir. Ama uzun süre evde, arkadaşsız kalmaktan çok sıkılmaktadır. Önce, dalgın, kaba ve bencil komşuları Süheyla Hanım, ardından da dayısı onu ziyarete gelir. Dayısı, sıkılmasın diye, ona, dördü kız, üçü erkek olmak üzere, kağıttan kağıt bebekler keser. Dayısı, Aydan’a kağıt bebeklerle konuşursa, onların canlanıp kendisine arkadaşlık edeceklerini söyler.

Aydan denileni yapar. Kağıt bebekleri sever, onlara isimler verir. Gerçekçi bir atmosferde başlayan oyun fantastik bir hal almaya başlar. Kağıt bebekler canlanır (oyuncularla). Süheyla Hanımın ve Aydan'ın dayısının başka kılıklarla karşımıza çıkmalarından, bu fantezinin bir rüya olduğu sonucuna varırız.

Kağıt bebekler Aydan'la arkadaş olur. Ancak onunla oyunlar oynayamazlar. Çünkü kağıttan bebeklerin elleri, kağıttan kesildikleri gibi, birbirine yapışıtır. Hep birlikte yanıt verirler, birlikte hareket ederler. Buna çok üzülen Aydan, "dört kişi gibisiniz ama dört kişi değilsiniz, üç kişi gibisiniz ama üç kişi değilsiniz. Size ayrı ayrı isimler vermekle çok hata etmişim, çünkü sizler, sizler bir tek kişisiniz. Ne korkunç şey bu...” der. Bu konuda onları da bilinçlendirir. “Ah şu ellerinizi ayırabilseydiniz birbirinden, o zaman ayrı ayrı düşünebilirdiniz. Yedi ayrı kişi olurdunuz o zaman. O zaman, birbirinize bilmece sorabilirdiniz. Başka başka yerlerde, değişik şeyler öğrenebilir, değişik şeyler düşünür ve düşüncelerinizi tartışabilirdiniz" der. Bebekler, birbirlerinden ayrılmak, karar ve eylemlerinde özgür olmak isterler ancak birbirlerinden nasıl kopacaklarını bilememektedirler.

Sorunu çözmesi için Kağıt Perisi'ni çağırırlar. Ancak Kağıt Perisi, bu sorunu kendisinin değil Kağıt Ustası'nın çözebileceğini söyler.

Kağıt bebeklerle Aydan, Kağıt Ustası'nı bulmak üzere yola çıkarlar. Onları çeşitli engeller, serüvenler beklemektedir.

Önce, Mikrotoslar çıkar önlerine. Bir çeşit mikrop olan bu yaratıklar, çocukların temizlikten yana tutum almaları, temizlikle ilgili sözler söylemeleri üzerine yollarından çekilirler.

Ardından, söz doktoru ile karşılaşırlar. Söz doktoru çocukların ağızlarını kontrol eder. Daha önce söylenmiş olup da ağızlarında sıkışıp kalan sözleri bir çeşit kerpetenle söküp almaktadır. Nitekim, Aydan'ın daha önce Süheyla Hanım için söylediği kötü sözler, ağzında kağıt parçacıkları olarak sıkışıp 
kalmıştır. Söz doktoru onları temizler, Aydan da o sözlerden, onları bir daha geri almamak üzere, gönüllü olarak vazgeçer. Yollarına devam ederler.

Önlerine çıkan yeni engel, Kağıt Cadısı'dır. Süheyla Hanım Kağıt Cadısı kılığında çıkar karşılarına. Yalnızlıktan sıkılan, iskambil kağıdıyla fal bakan Kağıt Cadısı, iskambil kağıtlarıyla oyun oynamak için kendisine arkadaş aramaktadır. Çocukların gelmesine bu nedenle sevinir. Ne var ki çocuklar iskambil bilmedikleri gibi orada oyalanmaya da niyetleri yoktur. Bir an önce gitmek isterler. Kağıt Cadısı onlara engel olmaya çalışır. Engeli aşmak için ona şartlı bulmacalar, bilmeceler sorarlar. Kağıt Cadısı bu bilmecelere doğru yanıt veremez. Güçlükle de olsa bu engeli de aşarlar.

Sonunda, Kağıt Ustası'na ulaşırlar. Aydan'ın dayısı, Kağıt Ustası kılığında çıkar karşılarına. Aydan, Kağıt Ustası'na durumu anlatır. Kağıt bebekler de, ayrılmak istediklerini, tek başlarına davranmak istediklerini belirtirler. Bunun üzerine, Kağıt Ustası, "Gerçek insan olarak, hepinizin ayrı birer kişiliğiniz olmalı. Ayrı ayrı düşünceleriniz, ayrı ayrı fikirleriniz, ayrı ayrı yetenekleriniz olmalı. Evet, sizleri birbirinizden ayırmalıyım. (Çocuklar sevinç çığlıkları atar) Ama dilerim yürekleriniz hep bir olsun. Ayrı yerlerde, farklı düşüncelerde olsanız bile dostluk bağınız, yürek bağınız hiç kopmasın” der ve onları ayırır. Bundan böyle birbirlerinden bağımsız hareket edecekler, tek başlarına karar verip eyleme geçecekler ancak aralarında yine de dostluk olacaktır.

Simgeler ve işlevleri: Yapışık kağıt bebekler, özgür ve özgün bireylerden oluşmayan toplumu; Kağıt Cadısı, bencillik ve yalnızlığın yarattığı kötülüğü; söz doktoru dil ve ahlak eğitimcisini; kağıt ustası bireyin yaratılmasına katkıda bulunan sanatçıyı simgeler niteliktedir.

Yorumlama: Oyunda bir tek yerde bile "birey" ya da "bireyleşme" sözcükleri kullanılmamıştır. Ancak, oyun bireyleşme üzerinedir. Soyut olan bu kavram çocuklar için somut olarak sahnede ifade edilmiştir. Bu da önemli bir yazarlık başarısıdır.

Aydan, iyi bir aile tarafından birey olarak yetiştirilmektedir. Bitişik olan kağıt bebeklerse, canlandıklarında birbirlerinden bağımsız hareket edememişlerdir. Bireysel kararları, bireysel iradeleri yoktur. Bu nedenle kararsız, hareketsizdirler. Bir şey yapmaya kalkıştıklarında ya bunu yapamamakta ya da tökezlemektedirler. Bir "sürü”nün "haleti ruhiyesi” içindedirler. Çınaroğlu, kabile, ümmet ya da milliyet olarak hareket eden, özgür bireylerden oluşmamış olan toplumlara eleştiri getirmekte, çağdaş bir değer olan "birey", "bireyleşme"yi öne çıkarmaktadır. Ancak bu "bireycilik", "bencillik" değildir. Oyunun sonunda Kağıt Ustası'ın ağzından dile getirildiği gibi, birey oldukları halde birlikte de hareket edebilecekler, aralarındaki bağı koparmayacaklardır. Özgür bir toplum da özgür bireylerden oluşabilir ancak. Öte yandan bireyleşemeyen kişiler toplumsallaşamaz da. Birey olmak da kolay değildir. Uzun yollar aşmak, çetin engeller geçmek gerekmektedir. Ancak buna değecektir. 
Bununla birlikte, bireyleşme serüveni içinde karşılarına çıkan engellerin bireyleşme ile ilgili olmaması oyunun değerini azaltmaktadır. Engeller, başka konularla, temizlik ve ahlakla ilgili engellerdir. Bu engellerin de, bireyleşme ile ilgili olmaları, bireyleşmenin önündeki engeller olarak sıralanmaları ve mücadeleyle aşılmaları oyunun değerini daha da artırmış olurdu.

\section{Konu: Bireyleşme}

Önerme: Bireyleşmek önemlidir. Bireyleşmenin önündeki engeller çabayla, sabırla ve dirençle aşılmalıdır.

\section{SONUÇ:}

Bazı oyunlarında, anlam açısından bazı pürüzler bulunsa da, oyunlarının genelinde, Çınaroğlu'nun anlamı çok önemsediği, bilinçli bir çabayla onu yarattığı, yaratılan bu anlamlarınsa çağdaş değerlerle örtüştüğü gözlemlenmektedir.

Ele aldığımız bu altı oyununda, eşitlikçi ve barışçıl bir dünya tasarımı sunduğu, bireyleşmeyi, özgün olmayı, yaratıcı olmayı, paylaşmayı öne çıkardığı, bu değerleri yücelttiği görülmektedir.

Giriş bölümünde, değindiğimiz çağdaş değerlerden insan hakları, bireyleşme, özgürlük, eşitlik, demokrasi, bilimsellik, hukukun üstünlüğü, barış, uzlaşma, çevre duyarlılığı gibi değerlerden, insan hakları, bireyleşme, özgürlük, eşitlik, demokrasi, barış değerlerini, çocuklar ve gençler için, çağdaş bir bakış açısıyla ele aldığı ve işlediği sonucuna ulaşıyoruz. Buradan hareketle, Çınaroğlu'nun çağının sözcüsü bir sanatçı/yazar olarak, çağının değerlerini yapıtlarında işleyerek yücelttiğini, bu nedenle çağdaş bir yazar olduğunu söyleyebiliriz.

\section{Kaynaklar}

Aksan, D. (1999). Anlambilim. Ankara: Engin Yayınevi.

Çınaroğlu, A. (1996). Miğfer. İstanbul: Uçanbalık Yayınları.

Çınaroğlu, A. (1998). Boş Kaplumbağa. İstanbul: Uçanbalık Yayınları.

Çınaroğlu, A. (2003). Tembel Fare Tini. İstanbul: Uçanbalık Yayınları.

Çınaroğlu, A. (2003). Hoş Geldin Esin Perisi. İstanbul: Uçanbalık Yayınları.

Çınaroğlu, A. (2004). Kim Demiş Niye Demiş. İstanbul: Uçanbalık Yayınları.

Çınaroğlu, A. (2005). Kâ̆̆ıt Şenliği. İstanbul: Uçanbalık Yayınları.

Eagleton, T. (1996). İdeoloj, (Çev: Muttalip Özcan). İstanbul: Ayrıntı Yayınları.

Egri, L. (2004). Piyes Yazma Sanatı (Çev: Suat Taşer). İstanbul: Papirüs Yayınevi.

Williams, R. (1990). Marksizm ve Edebiyat (Çev: Esen Tarım). İstanbul: 1.B. Adam Yayınları. 


\section{Summary \\ An Ideological Approach to Ayla Çınaroğlu's \\ Plays for Children and the Young \\ Hasan ERKEK.}

Anadolu University

This paper attempts to treat and evaluate Ayla Çınaroğlu's plays for children and young people purely from ideological (not from technical and aesthetical) perspective. The plays included in this study are Miğfer (The Helmet), Boş Kaplumbağa (The Hollow Turtle), Tembel Fare Tini (Lazy Mouse Tini), Hoş Geldin Esin Perisi (Wecome Fairy of Inspiration), Kim Demiş Niye Demiş (Who Said It For What Purpsose) and Kağıt Şenliği (Paper Festival). Each work is read in depth and evaluated so as to find out the ideological aspects of plays. The results are questioned with respect to contemporary values.

For the purpose of this study, ideology is considered the meaning aspect of plays treated in the study. The ideological aspect of a work is concerned with how meaning is created in a work, how it is organized, which meaning(s) is created in the given work, and concordance and contrast relations of meaning/meanings with some though systems.

In all works, we encounter meaning as little semantic units, not as a holistic system. Through reading works freely and methodologically, readers are able to relate semantic units with each other, come to an interpretation, and then reach the deep meaning of the play.

Ideology is abstract because it is related with thought and meaning. However, works of art are concrete. Abstract concepts and thoughts are concretized, and added into works of art. The meaning created in a concrete work of art is discovered through reading, interpreting and thus abstracting.

In dramatic works, meaning is created through characters, space, time, actions-acts, words, symbols, and so on. It is required to consider and interpret these elements when reading the works.

The topic and main idea of each play is determined on the basis of reading and interpreting processes. This is the most distilled state of meaning aspect in a play.

Topic and main idea are at an abstract and conceptual level. They each cover a generalization. There is a firm relationship between topic and main idea. The main idea is necessarily related with topic.

Discovering topic and main idea is not as easy as it is considered. It is possible to discover as many topics and main ideas as the number of readers of a work because topic and main idea are the result of 
interpretation. Works of art do not have a single ideal interpretation. Nevertheless, it is expected that all interpretations - topics and main ideas identified by various readers - are based on the text and do not extend over the limits of the text.

After the ideological aspect of a work is discovered, it is possible to reach the ideology of the writer on the basis of this discovery (certainly, it is required to read all works of a writer methodologically to do this), and this ideology can be questioned with respect to contemporary values.

Among the main values of our age are human rights, individualization, freedom, equality, democracy, scientificity, rule of law, peace, compromise, and environmental sensitivity.

When Ayla Çınaroğlu's plays for children and the young are read and interpreted in terms of topic and main idea, it is found out that the topics and main ideas of these plays are related with each other and that meaning is mostly created consistently.

Meaning is supported by characters, words and symbols as well as the narrative, and thus becomes more vivid. It is also noted that concrete elements are used for creating meaning, and that concepts are avoided.

The writer puts emphasis on peace in The Helmet, originality and respect for differences in the Hollow Turtle, avoiding "othering" and sharing in Lazy Mouse Tini, creativity and avoiding detachment from childhood in Welcome Fairy of Inspiration, eradication of exploitation in the world and establishment of equality in Who Said It For What Purpose, and individualization in Paper Festival.

Consequently, it is observed that, despite the existence of some defects about meaning, Çınaroğlu attaches importance to meaning, and creates meaning through intentional efforts; and that these meanings identify with contemporary values.

In these six plays, the writer presents a design of world dominated by equality and peace, and emphasizes and upholds values such as individualization, originality, creativity, sharing and so on.

We can conclude that she treats values of human rights, individualization, freedom, equality, democracy and peace from a contemporary perspective for children and young people.

On the basis of this finding, we can say that Çınaroğlu, as a writer who is the mouthpiece of her age, treats and upholds the values of her age in her works and that she is a contemporary writer. 
